Proc. of the X Int. Conf. - Ion Implantation and other Applications of Ions and Electrons, Kazimierz Dolny 2014

\title{
Composition and Microstructure of Surface Layers Produced by Ion Beam Assisted Deposition of Metals from a Pulsed Arc-Discharge Plasma onto Aluminum Substrates
}

\author{
V.V. Poplavsky ${ }^{a}, *$ F.F. Komarov ${ }^{b}$, V.G. Luhin ${ }^{a}$, V.V. Pil'Ko ${ }^{b}$ And J. Partyka ${ }^{c}$ \\ ${ }^{a}$ Belarusian State University of Technology, 13a, Sverdlov Str., 220006 Minsk, Belarus \\ ${ }^{b}$ Belarusian State University, 4, Nezavisimosti av., 220030 Minsk, Belarus \\ ${ }^{c}$ Lublin University of Technology, Nadbystrzycka 38a, 20-618 Lublin, Poland
}

\begin{abstract}
Ion beam assisted deposition of alloying metals $(\mathrm{Zn}, \mathrm{Cd}, \mathrm{Zr}, \mathrm{Cr})$ onto pure aluminum and aluminum alloy substrates from the plasma of a pulsed arc discharge for the purpose of materials corrosion stability was carried out. The Rutherford backscattering spectrometry, electron backscatter diffraction, scanning electron microscopy, and electron probe microanalysis methods were applied to investigate composition and microstructure of the prepared layers. It was found that the obtained layers are characterized by amorphous atomic structure and contain the atoms of deposited metal, substrate material components, as well as impurities of oxygen and carbon; their thickness was measured to be $\approx 30-100 \mathrm{~nm}$.
\end{abstract}

DOI: $10.12693 /$ APhysPolA.128.946

PACS: $68.37 . \mathrm{Hk}, 68.55 . \mathrm{Nq}$

\section{Introduction}

Ion-beam treatment of substances provides the opportunity to implant controlled amounts of a dopant into their surface layers under non-equilibrium conditions. Ion-beam modification of the materials whose operating abilities, particularly physicochemical (corrosion and catalytic) properties, are mainly controlled by the surface composition is of particular interest.

The goal of this work is to study composition and microstructure of surface layers produced by the ion beam assisted deposition (IBAD) of alloying metals ( $\mathrm{Zn}, \mathrm{Cd}$, $\mathrm{Zr}, \mathrm{Cr}$ ) onto pure aluminum and aluminum alloy D16 substrates for the purpose of achieving corrosion stability of the materials.

Relevance of the study is provided due to the fact that the galvanic deposition of the protective metallic coatings is associated with serious environmental and technical issues. Corrosion properties of aluminum substrates with IBAD produced layers were tested with the use of electrochemical polarization method in $3 \% \mathrm{NaCl}$ solution $[1,2]$. Appreciable increase of corrosion stability was observed after deposition of alloying metals on aluminum and aluminum alloy. In the previous works [3-5] it was also found that the ion beam assisted deposition in the proposed mode of catalytic metals on a substrate of aluminum, titanium and tantalum makes it possible to form layers, characterized by a high electrocatalytic activity.

${ }^{*}$ corresponding author; e-mail: vasily.poplav@tut.by

\section{Experimental details and results}

The investigated layers with the use of ion beam assisted deposition of alloying metals ( $\mathrm{Zn}, \mathrm{Cd}, \mathrm{Zr}, \mathrm{Cr}$ ) onto pure aluminum A7 and aluminum alloy grade D16 substrates were obtained. The IBAD method is characterized by the use of deposited-metal ions as assisting ones. Metal deposition and mixing between the precipitable layer and the surface substrate atoms accelerated by ions of the same metal were conducted from a neutral vapour fraction and the vacuum-arc discharge plasma of a pulsed electric arc ion source, respectively. The discharge pulse frequency was $50 \mathrm{~Hz}$. For acceleration of the assisting metal ions the voltage of $10 \mathrm{kV}$ was used. Vacuum of $10^{-2} \mathrm{~Pa}$ was maintained in the working chamber. Preliminary preparation of samples included mechanical polishing of substrates with the use of abrasive polishing paste, washing and degreasing in ethanol.

The composition and microstructure of the obtained layers were experimentally investigated with the use of the Rutherford backscattering spectrometry (RBS), scanning electron microscopy (SEM), electron probe microanalysis (EPMA), and electron backscatter diffraction (EBSD) methods.

In the RBS technique, the surface layers were examined by measuring the spectra of scattered ${ }^{4} \mathrm{He}$ ions $\left(E_{0}=1.0\right.$ or $\left.1.3 \mathrm{MeV}\right)$ using an $\mathrm{AN}-2500$ accelerator (High Voltage Engineering Europe). During recording of the spectra, the analyzing particle beam was normally incident to the sample surface and the scattering angle was $170^{\circ}$. The energy resolution of the spectrometer with a surface-barrier silicon detector was $18 \mathrm{keV}$. Standard processing of the RBS spectra was performed. The structure of the surface layers was examined by means of JEOL JSM-5610 LV scanning electron microscope. 
The electron-microscopic analysis of the surfaces was accompanied by EPMA using the dispersion of quantum energy in characteristic X-rays emitted by the atoms of elements included in the composition of the layer under consideration and silicon-lithium detectors. The cards of elements distribution on a surface of the investigated layers were also obtained. The energy of the electrons scanning over the studied materials' surfaces was $20 \mathrm{keV}$. The EBSD investigations were carried out using an HKL Channel 5 Premium EBSD phase-analysis attachment and a LEO 1455 VP microscope. In the EBSD technique, acquisition of information on the crystalline structure of a material is based on the diffraction of diffusely backscattered electrons at a crystal lattice. The primary electron beam with the energy $20 \mathrm{keV}$ is incident to the sample surface at an angle of $70^{\circ}$.

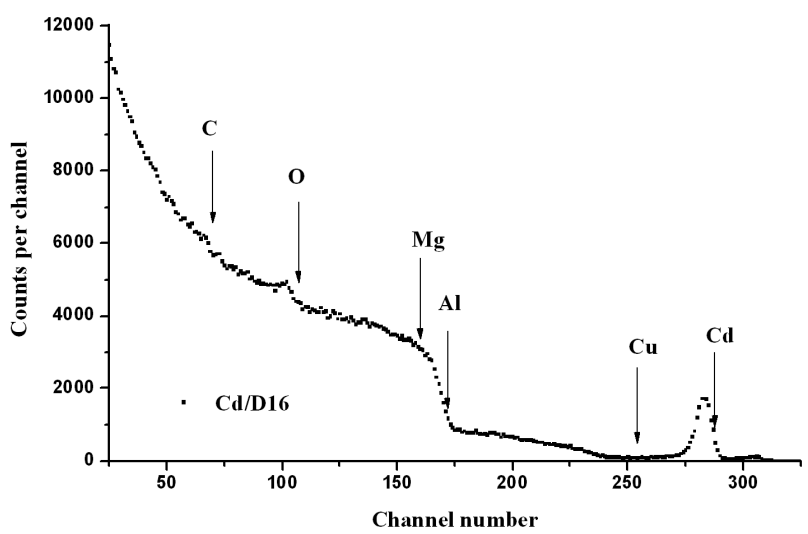

Fig. 1. RBS spectrum of ${ }^{4} \mathrm{He}$ ions $\left(E_{0}=1.0 \mathrm{MeV}\right)$ scattered from the aluminum alloy D16 surface with a layer prepared by cadmium IBAD. $(N t)_{\mathrm{Cd}}=4.6 \times$ $10^{15} \mathrm{~cm}^{-2} ;(N t)_{\mathrm{O}}=2.9 \times 10^{16} \mathrm{~cm}^{-2} ;(N t)_{\mathrm{C}}=$ $1.7 \times 10^{16} \mathrm{~cm}^{-2}$.

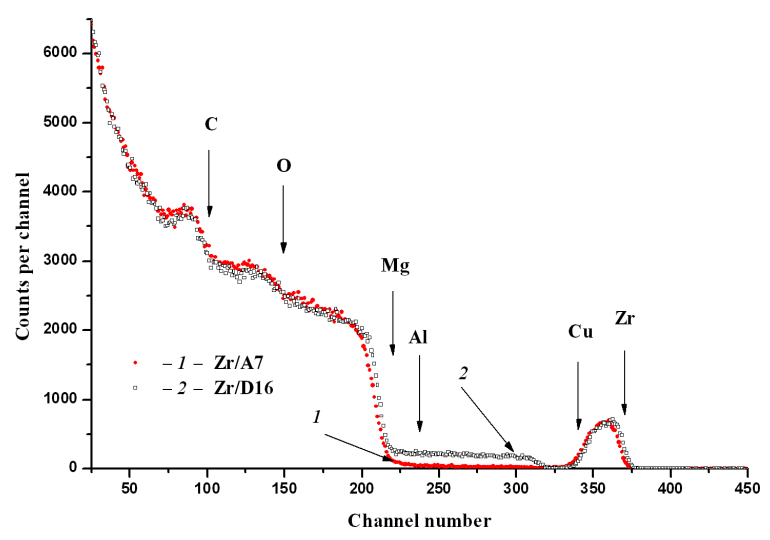

Fig. 2. RBS spectra of ${ }^{4} \mathrm{He}$ ions $\left(E_{0}=1.3 \mathrm{MeV}\right)$ scattered from the aluminum A7 (1) and alloy D16 (2) surfaces with layers prepared by zirconium IBAD. 1: $(N t)_{\mathrm{Zr}}=4.5 \times 10^{16} \mathrm{~cm}^{-2} ;(N t)_{\mathrm{O}}=2.0 \times 10^{17} \mathrm{~cm}^{-2} ;$ $(N t)_{\mathrm{C}}=7.0 \times 10^{17} \mathrm{~cm}^{-2}, 2:(N t)_{\mathrm{Zr}}=4.1 \times 10^{16} \mathrm{~cm}^{-2}$; $(N t)_{\mathrm{O}}=1.1 \times 10^{17} \mathrm{~cm}^{-2} ;(N t)_{\mathrm{C}}=5.9 \times 10^{17} \mathrm{~cm}^{-2}$.

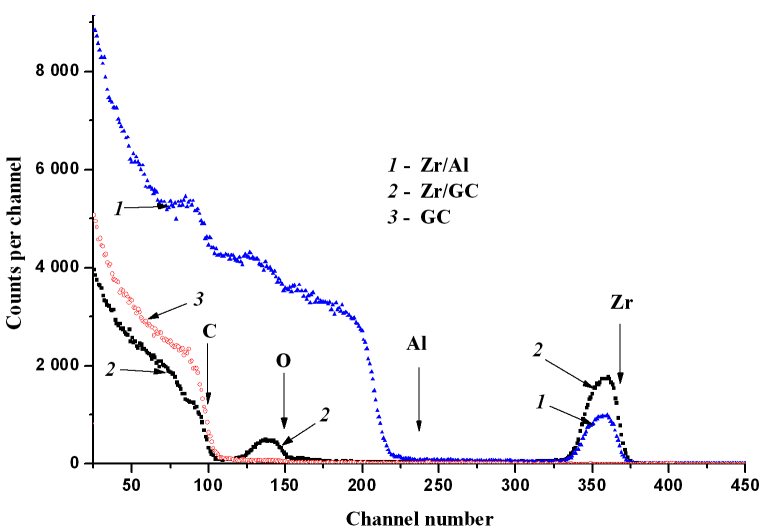

Fig. 3. RBS spectra of ${ }^{4} \mathrm{He}$ ions $\left(E_{0}=1.3 \mathrm{MeV}\right)$ scattered from the aluminum A7 (1) and, for comparison, from the glassy carbon (GC) (2) surfaces with layers prepared by zirconium IBAD, and 3 from the glassy carbon substrate. 1: $(N t)_{\mathrm{Zr}}=4.5 \times 10^{16} \mathrm{~cm}^{-2}$; $(N t)_{\mathrm{O}}=2.0 \times 10^{17} \mathrm{~cm}^{-2} ;(N t)_{\mathrm{C}}=7.0 \times 10^{17} \mathrm{~cm}^{-2}$, 2: $(N t)_{\mathrm{Zr}}=3.5 \times 10^{16} \mathrm{~cm}^{-2} ;(N t)_{\mathrm{O}}=1.8 \times 10^{17} \mathrm{~cm}^{-2}$.

Figures 1-3 present the experimental RBS spectra of ${ }^{4} \mathrm{He}$ ions scattered from the investigated surfaces with the IBAD prepared layers. The layers contain atoms of deposited metals, components of the substrate material $(\mathrm{Al}, \mathrm{Cu}$, and $\mathrm{Mg}$ in the case of alloy D16), and oxygen and carbon as impurities. Marked by the arrows in the spectra analyzer channel the numbers correspond to the energy of ${ }^{4} \mathrm{He}$ ions backscattered by the atomic nuclei of elements on the samples surface. Availability of oxygen is agreed of oxide film on the initial aluminum surface and can be captured along with carbon in the residual atmosphere of the vacuum chamber, which contains a volatile hydrocarbon fraction of the working fluid of a diffusion pump. According to the RBS data when the content of the deposited metal atoms $(N t)_{\mathrm{Me}}$ is of the order of $10^{15} \mathrm{~cm}^{-2}$ - thickness of formed layer is $\approx 10 \mathrm{~nm}$ (Fig. 1). Layers with the metal content $\approx 10^{16} \mathrm{~cm}^{-2}$ reach a thickness of $\approx(100-200) \mathrm{nm}$ (Figs. 2,3$)$. Depending on the content of deposited metal atoms concentration of deposited metals in the distribution maximum located at a depth of $\approx(10-20) \mathrm{nm}$ is $\approx(1-15)$ at.\%. Contents of oxygen $(N t)_{\mathrm{O}}$ and carbon $(N t)_{\mathrm{C}}$ atoms in the obtained layers are much higher (Figs. 1-3).

The electron-microscopic studies demonstrate that the microstructure and morphology of the layers almost repeat the structure of an aluminum substrate (Figs. 4a,b, 5a). EPMA reveals that the layers contain the atoms of deposited metal, components of substrate material, oxygen, and carbon. An analysis of the distributions of elements over the specimen surface demonstrates that the atoms of the elements entering into the layers composition are uniformly distributed over the surface (Figs. 4c,d, 5b-d). Deposited metal inclusions of several $\mu \mathrm{m}$ in size are detected on the coating surface (Figs. 4, 5), which is caused by the deposition of metal droplets from the arc discharge of the ion source. 


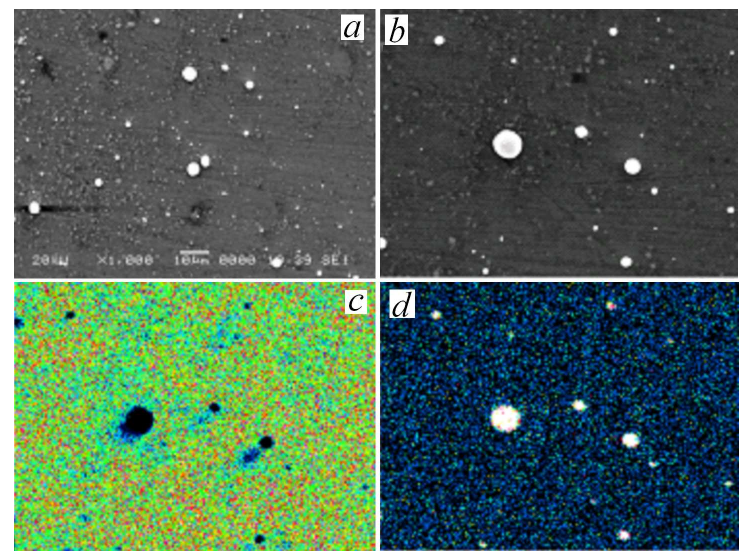

Fig. 4. SEM images (a), (b) of the layer prepared by zirconium IBAD onto the aluminum alloy D16 and distribution on the surface of: (c) aluminum; (d) zirconium.

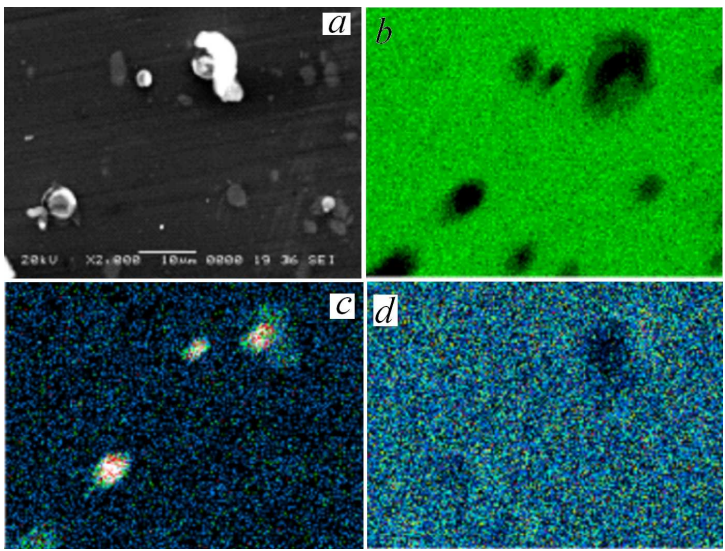

Fig. 5. SEM image (a) of the layer prepared by zinc IBAD onto the aluminum alloy D16 and distribution on the surface of: (b) aluminum; (c) zinc; (d) oxygen.
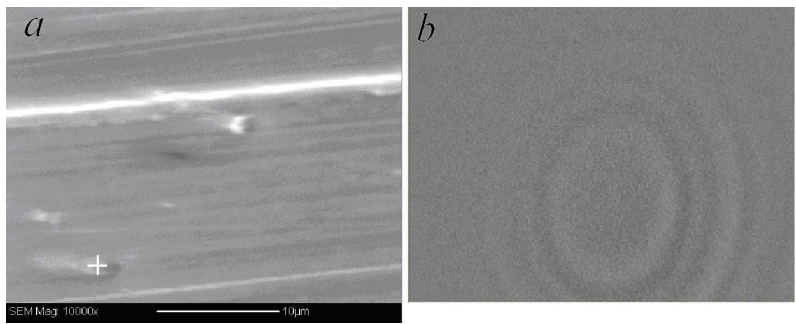

Fig. 6. SEM image (a) of the layer prepared by chromium IBAD onto the aluminum and diffraction pattern (b) corresponding to the diffraction of electrons scattered from the layer.

Figure 6 illustrates the diffraction of electrons backscattered from the surface layer prepared by the IBAD of chromium on aluminum. The diffraction pattern (Fig. 6b) indicates that the layer atomic structure has no long-range order.

\section{Conclusions}

It was established that the obtained layers are characterized by amorphous atomic structure and contain deposited metal atoms, substrates material components, as well as impurities of oxygen and carbon; their thickness reaches $\approx 100 \mathrm{~nm}$. Oxygen and carbon appear due to both the residual atmosphere of the working vacuum chamber and sorption processes. It follows from the analysis of the distribution patterns of elements that atoms of the elements included in the layer composition are almost uniformly distributed over their surface. At the same time, the surfaces contain deposited metal inclusions with the sizes of several $\mu \mathrm{m}$, which arise from the precipitation of metal droplets from the arc discharge of the ion source. According to the RBS data the content of deposited metal atoms in the prepared layers is $\approx n \times 10^{16} \mathrm{~cm}^{-2}$. Due to amorphous atomic structure and $\mathrm{nm}$ thickness, it is practically impossible to identify the phase composition of the obtained multicomponent layers.

The advantages of the proposed IBAD method are as follows: possibility of forming a cohesive thick layer on a substrate at low alloyed metal consumption, relative simplicity, absence of an inert gas (which can result in blistering and, thus, the fracture of the modified layer) in the layer composition, against dual (metal-deposition $+\mathrm{Ar}^{+}$-mixing) IBAD or magnetron sputtering methods. The method can be used as an alternative to the most problematic electroplating technology.

\section{References}

[1] V.V. Poplavsky, V.G. Matys, I.M. Bely, in: 3rd Int. Congress on Radiation Physics and Chemistry of Condensed Matter, High Current Electronics and Modification of Materials with Particle Beams and Plasma Flows, Tomsk (Russia) 2012, National Research Tomsk Polytechnic University, Institute of High Current Electronics SB RAS, Abstracts, Tomsk 2012, p. 400.

[2] V.V. Poplavsky, V.G. Matys, in: Int. Congress on Energy Fluxes and Radiation Effects, Tomsk (Russia) 2014. National Research Tomsk Polytechnic University, Institute of High Current Electronics SB RAS, Abstracts, Tomsk 2014, p. 297.

[3] V.V. Poplavskii, T.S. Mishchenko, V.G. Matys, Techn. Phys. 55, 296 (2010).

[4] V.V. Poplavskii, T.S. Mishchenko, V.G. Matys, J. Surf. Invest. X-ray Synchr. Neutron Techn. 4, 576 (2010).

[5] V.V. Poplavskii, T.S. Stel'makh, V.G. Matys, J. Surf. Invest. X-ray Synchr. Neutron Techn. 6, 748 (2012). 